\title{
El estigma en psiquiatría: un repaso desde sus antecedentes, a su actualidad
}

\author{
Juan Manuel Ferraro ${ }^{1}$ \\ 1. Licenciado en psicología. Hospital Provincial de Rosario, Argentina. \\ Autor correspondiente: Juan Manuel Ferraro, E-mail: jmsdferraro@hotmail.com
}

\begin{abstract}
Resumen
La Organización Mundial de la Salud estimaba que, al 2001, 450 millones de personas padecían algún trastorno mental. Pero de todas ellas, sólo una pequeña minoría recibía tratamiento, en parte debido al estigma. Es por eso que en su informe insta a la realización de campañas de educación respecto a la temática del estigma, y a su combate. El presente artículo lo que intenta es un abordaje histórico del estigma que busque dar cuenta de sus inicios, su transcurrir, y su actualidad. De todo ello desprendemos algunas reflexiones al respecto que buscamos que nos expliquen su naturaleza, y así un posible camino para comenzar a desmontarlo. Vemos en el desarrollo cómo estuvo presente para con la locura desde antes del nacimiento de la psiquiatría, y cómo con este advenimiento se pudo aportar las luces del conocimiento que redujeran el oscurantismo del periodo pre-médico. Vemos en la actualidad cómo sigue vigente, expresándose en comentarios del día a día, e incluso en algunas expresiones que se suponen artísticas. La pregunta que aparece en todo momento es: ¿cómo salir del estado actual? Esperamos que nuestro trabajo nos aporte algún atisbo de respuesta.
\end{abstract}

Palabras clave: Estigma - Historia del estigma - Estigma en medicina - Estigma y trastornos mentales.

STIGMA IN PSYCHIATRY: A REVIEW FROM ITS BACKGROUND, TO ITS CURRENT SITUATION

\begin{abstract}
The World Health Organization estimated that, by 2001, 450 million people suffered from a mental disorder. But of all of them, only a small minority received treatment, partly due to stigma. That is why the report urges the realization of education campaigns regarding the topic of stigma, and its combat. The present article makes an historical approach of stigma that aims to show its beginnings, its course, and its current situation. From there, we propose some thoughts trying to find a way to explain its nature, and maybe to begin disassembling it. We see how it was present towards madness since before the birth of psychiatry, and how with this advent, the lights of knowledge reduced the obscurantism of the pre-medical period. We see today how it is still active, expressing itself in daily comments, and even in some expressions that are supposed to be artistic. The question that appears at alltimes is: how can we get out of the current state? We hope that our work brings us a glimpse of response.
\end{abstract}

Keywords: History - Stigma - Medicine - Stigmas and mental disorders. 


\section{Introducción}

El estigma en psiquiatría es una problemática actual de creciente importancia a nivel internacional. Lo encontramos en el centro del informe de la Organización Mundial de la Salud, Salud mental: nuevos conocimientos, nuevas esperanzas (1), donde se destaca que de los 450 millones de personas estimadas que padecían algún trastorno mental en el año 2001, sólo una pequeña minoría de ellos recibían tratamiento, en parte debido al estigma.

Esto indica la relevancia de la temática: no se trata únicamente del inconmensurable y sumamente variable padecer subjetivo que provoca el estigma, tanto para el paciente mismo como para sus familiares -y que se suma al padecer propio de la enfermedad mental-, sino que a su vez se transforma en un problema del acceso a la salud de los padecientes, porque los disuade de buscar asistencia.

Nuestra mirada al respecto es una: el avance del conocimiento puede hacer las veces de un antídoto contra los prejuicios y los estigmas. Por ello nos proponemos debatir sobre este tema, intentando que nuestro aporte se traduzca en una mayor comprensión del estigma, y tal vez en su desmontaje nos provea de alguna vía de salida posible, cuyo correlato sea una mejor calidad de vida para nuestros pacientes, y la mayor predisposición a que busquen la asistencia adecuada para el tratamiento de la patología que los aqueja.

Lo intentaremos mediante el indagar, etimológica e históricamente, la naturaleza misma del estigma. Evaluaremos sus relaciones con la medicina, y puntualmente con la psiquiatría. Plantearemos para el debate nuestras reflexiones, entre las que se cuenta una revalorización del concepto de "paciente", por creer que la medicalización de la enfermedad mental ha impreso un mayor conocimiento de la misma y encarado al comienzo un proceso importante de desestigmatización; aunque luego algunas prácticas mismas de nuestras disciplinas se hayan vuelto ellas mismas estigmatizantes. Por tal motivo es que efectuamos un retorno a nuestros orígenes, rescatando los nombres y las ideas de los primeros psiquiatras, en quienes creemos hallar indicado el espíritu y la senda que nos conduzca al derribamiento de esta problemática.

\section{El estigma explicito e implícito en medicina}

El término estigma proviene etimológicamente del latín, y hace referencia a una "Marca impuesta con hierro candente; señal de infamia" (2). Es un término también utilizado en medicina, haciendo referencia a "Cualquier marca o peculiaridad mentales o físicas que apoyan la identificación del diagnóstico de un trastorno" (3).

Esta última definición, al hacer mención a la marca o peculiaridad mental, nos comienza a acercar a aquella parcela particular, del campo alguna vez inaugurado por Hipócrates, que es la medicina mental o la psiquiatría. Pero hay un acceso aún más directo que empareja al estigma con la psiquiatría, siendo explicito e implícito a la vez.

Aquél acceso más directo y explícito de lo que se ha dado en llamar el estigma en la psiquiatría, lo tiene por la hermana mayor y rica de ésta, la neurología, en un encuentro parisino con su bête noire: las histerias.

La historia tiene tintes novelescos. París de finales del siglo XIX en La Salpêtrière. En algún pabellón cualquiera, una paciente llega manifestando haberse quedado ciega de repente. El médico se acerca para examinar los reflejos de acomodación y fotomotor con la ayuda de algún estímulo visual y lumínico. Las pupilas, al contrario de lo que manifestaba en su discurso la paciente, se mostraban normorreactivas. Hay miosis con el estímulo lumínico, y midriasis en su cesación. Además, muestra variaciones el tamaño de la pupila al acercar o alejar el objeto. La ceguera comienza a ser poco probable. Sin embargo, la paciente insiste: no ve.

El médico comienza a desconfiar. Llega incluso a sospechar que ni siquiera la anatomía patológica hubiera mostrado alguna alteración de la corteza visual que justificara lo enunciado por la paciente. El diagnostico le es claro: histeria.

Al no presentarse ninguna alteración orgánica que justificara el cuadro, ese era el diagnostico. Como aditamento, se le adosaba un comentario que la desterraba de todo tratamiento médico posible: "Las histéricas son simuladoras. No hay nada que curar, no hay nada que tratar. ¡Au revoir, mademoiselle!"

En esta anécdota novelada, pero no por ello menos cierta -y seguramente acaecida alguna vez- podemos ver cómo se van entrelazando las definiciones del estigma. Por un lado, tenemos la acepción médica como marca o peculiaridad mental que determina un diagnóstico. Pero, por el otro, aquella acepción del estigma que hace señal de infamia: “¡Histérica! ¡Simuladora!”

Tuvo que llegar Jean Martin Charcot para darles a las histerias dignidad médica y brindarles un estudio minucioso y una atención acorde a su arte sanitario.

Así presentó en sus Leçons du mardi a pacientes histéricas y fue desmenuzando sus diversas presentaciones clínicas hasta encontrar en ellas la estructura que formara un cuadro clínico, y así pudo describir el gran ataque -completo, con sus cuatro fases- y sus formas frustras (4).

Charcot no tenía dudas de que la histeria era un problema médico. "Y no se les ocurra decirle que es una simulación. Ni por asomo [...] Es preciso que se sepa que la histeria es una enfermedad psíquica, absolutamente" (4). Como tal, incluso proponía su debido tratamiento. "Hay que curarla", decía sobre un caso de parálisis de tal índole.

Teniendo en cuenta que la neurología de la época denominaba estigmas a los síntomas patognomónicos de la histeria (5), incluyendo principalmente trastornos de la sensibilidad, trastornos motores y trastornos psíquicos, podemos concluir que Charcot tomó un cuadro estigmatizado del cual incluso médicamente se hablaba de sus estigmas, y al brindarle su atención e interés, efectuó el gesto importantísimo de des-estigmatizarlo y devolverle a esos padecientes su dignidad médica.

Convirtió así a las histéricas de simuladoras en pacientes, de exiliadas del campo de la medicina a incluidas en su atención. 


\section{De los antecedentes del estigma, y de la psiquia- tría misma}

Acabamos de ver cómo en la neurología se contaba explícitamente con el término estigma para hacer referencia a los síntomas patognomónicos de la histeria, y cómo además se operaba para con este campo de la psicopatología implícitamente un proceso de estigmatización que dejaba fuera de toda atención sanitaria a aquellos pacientes padecientes de tal afección.

Pero podemos ahora entrar más en detalle y ver cómo el estigma para con la enfermedad mental está desde los orígenes mismos de la psiquiatría, e incluso aguardando su advenimiento.

Nos resultará claramente imposible un abordaje exhaustivo de toda la bibliografía al respecto de los momentos previos al nacimiento de la psiquiatría y de los diversos tratamientos llevados a cabo para con el vasto campo de las locuras. Por ello nos limitaremos tan sólo a un repaso a vuelo de águila de tal temática, del cual esperamos hacer una lectura crítica y extraer algunas conclusiones.

En nuestro recorrido hemos optado por llevarnos de la mano de ilustres nombres del gran panteón de la medicina mental. Nos referimos, y tan sólo por el recorte que nuestro trabajo amerita, a Philippe Pinel, Jean Étienne Dominique Esquirol y Jean Pierre Falret.

De las obras que nos han legado extraemos todo el período pre-médico de las locuras, sirviendo de base para ulteriores formulaciones.

Si bien Pinel no nos habla puntualmente de esto, su descendencia sí, y no habría descendencia jamás sin quien inaugure la progenie. Esquirol denuncia de entrada el descuido médico para con las locuras "El estudio de la alienación mental se ha descuidado tanto hasta nuestros días que aún sigue sin considerarse como un objeto de la medicina clínica" (6). Todo esto cambió con un hombre, quien les proveyó a los locos de dignidad médica convirtiéndolos de espectáculo, de bufones, de iluminados, de poseídos, en pacientes: Philippe Pinel. El mismo gesto de Charcot para con las histéricas, es el que supo hacer mucho antes Pinel para con los locos, en su más vasta generalidad. Inclusión de las histéricas en la atención médica en un caso; atención médica de los alienados mentales en el otro.

Aquel período pre-médico consistía, en resumidas cuentas, de los siguientes tratamientos dispensados (7).

Los locos en libertad eran el entretenimiento o de la plebe, siendo el bufón del pueblo, o de la realeza como los locos del rey. Al fin y al cabo el resultado era el mismo, pues, en ambos casos, tratábase de un espectáculo lamentable en el que los espectadores se mofaban de un padeciente. Algunos eran tomados como inspirados y "con ese título, se los rodeaba de privilegios, respeto y veneración"; mientras que, aun siendo del mismo géne- ro, algunos menos afortunados se los tomaba por posesos, y el tratamiento dispensado a ellos era el exorcismo $\mathrm{y}$ "suplicios para hacer que estos desgraciados denunciaran a su pacto con el diablo". ${ }^{1}$

Los que no estaban en libertad, eran encerrados en calabozos, donde, en aquél gran encierro que describiera años más tarde Michel Foucault (8), "habían sido confundidos con los criminales y él [Pinel] ${ }^{2}$ los elevó a la dignidad de enfermos" (7).

Por tanto, y para resumir, la locura había sido vista como inspiración divina, posesión demoníaca, espectáculo público o de la realeza, y también escoria social. Pero nunca, en ninguna de esas ocasiones, como objeto del estudio y tratamiento médico.

Hasta que llegó Pinel.

Su gesto no se agota en lo anecdótico de la liberación de las cadenas, inmortalizado en el famoso cuadro de Robert-Fleury $^{3}$. No es tan sólo mandar a quitar las cadenas de esa loca vestida de blanco y con la mirada perdida que se mantiene sostenida a su lado, sino también es denominar a aquella tirada en el suelo, sobre el margen derecho, y gorro frigio rojo, paciente, y por tanto, como plausible de atención médica.

En consecuencia, podemos concluir hasta aquí que la locura había sido estigmatizada, cubierta de ese manto de infamia, hasta Pinel. El primer gran golpe contra el estigma de la locura se dio, justamente, con el surgimiento de la psiquiatría.

Pero no fue suficiente. Ni Philippe Pinel en Francia, ni Johan Christian Reil en Alemania, ni Joseph Guislain en Bélgica, ni Vincenzo Chiarugi en Italia, fueron suficientes para acabar, de una vez por todas, con el estigma de la locura y hacerla concebir enteramente como un problema médico, y ya no más como motivo de burla, de difamación, de exclusión.

Falret se dio cuenta de esto, y por eso "Pese a tanta ciencia, tanta abnegación [por parte de Pinel y Esquirol] ${ }^{4}$ (...) queda aún mucho por hacer" (7). Y puso manos a la obra.

El estigma perduraba. La medicina no estaba dispuesta a acoger la naciente psiquiatría como una de sus especialidades, ni siquiera a introducirla dentro de su formación de grado. "Los propios cursos clínicos de las enfermedades mentales son objeto de numerosos prejuicios" (7), y por tanto, se abocó a "hacer ver que el estudio clínico de las enfermedades mentales es útil a todos los médicos".

Así como su maestro Pinel se ocupó de asestar el primer golpe contra el estigma sobre la locura por parte de la sociedad en general, Falret hizo lo propio, pero atacando el estigma sobre la locura por parte de la ciencia médica.

Su propuesta resultó ser el dispositivo de enseñanza clínica psiquiátrica por excelencia: la presentación de enfermos (7).

1- José Ingenieros nos indica que, así como en los europeos, entre los quichuas, guaraníes y araucanos, la locura “era atribuida a causas sobrenaturales y curada mediante prácticas de hechicería". En: Ingenieros J. La locura en la Argentina. Córdoba: Buenas Vista; 2005. p. 14.

2- Lo escrito entre corchetes es nuestro.

3- Pinel, médecin en chef de la Salpêtrière, délivrant les aliénés de leurs chaînes en 1795, es un cuadro del pintor francés Tony Robert-Fleury, 1886.

4- Lo escrito entre corchetes es nuestro. 
Pero este hombre no circunscribió la lucha contra el estigma solamente al ámbito de la formación de futuros profesionales, psiquiatras o no, sino que también se preocupó por el loco y su sociedad. Se preocupó por la reinserción, por qué acontecería con los pacientes una vez externados, para no caer en la misma situación del período pre-médico en la que el enfermo podía quedar en libertad a merced de viles ciudadanos que se mofaran y abusaran de su condición, propuso y dispuso de instituciones a medio camino que posibilitaran el retorno del otrora paciente, ahora externado, a su vida más cotidiana y habitual, con la Société de Patronage pour les Alienes sortis gueris de l'Hôpital de la Salpêtrière et Bicetre (7).

No obstante, y tal como aconteció con los nobles y admirables esfuerzos de sus maestros, el estigma persistió, y llega hasta el día de hoy.

A pesar de ello, podemos ver cómo en el rastreo histórico hemos podido encontrar cómo el estigma sobre la locura estuvo desde antes que surgiera la psiquiatría, pasando por los años de su nacimiento, hasta sus primeros pasos. Pareciera ser que, en definitiva, hablar del estigma de la locura y de la psiquiatría en sí misma, es hablar del mismo asunto.

No es una historia nueva, sino una historia de vieja data y que aún debe ser motivo de reflexión y de esfuerzos en la búsqueda de una solución posible.

\section{Reflexiones a partir de un testimonio de actuali- dad: ¿Qué vistes?}

Para dar muestra ahora del actual y creciente interés que despierta el estigma en psiquiatría, tenemos en primer lugar las campañas llevadas a cabo por la American Psychiatric Association en el reconocimiento y lucha contra él. En sus redes sociales resumen un poderoso pensamiento en una simple frase "La enfermedad mental no es nada de lo que avergonzarse. Es una condición médica, como cualquier otra enfermedad física" (9), y en sus sitios web cuentan con publicaciones sobre la misma temática $(10,11)$.

Hacemos mención a lo poderoso de semejante pensamiento en una tan simple frase, porque resume una verdad que, por obvia, termina siendo obviada. Es algo que es claro, pero que la sociedad aún parece indispuesta a aceptarla, e incluso, lamentablemente, algunos médicos se contagian de tal repulsión.

Es tan resistida la locura, tan estigmatizada, que ni siquiera los siglos que pasaron desde Pinel han revertido esa situación, por lo que la lucha nos conmina a todos los profesionales de la salud, en manera mancomunada, y sin caer en inútiles divisiones que separen una supuesta salud general de una supuesta e independiente salud mental, a su confrontación en busca de una salida posible.

Así como en nuestra práctica clínica escuchamos a nuestros pacientes, así haremos en esta ocasión, y escucharemos el testimonio mismo de un padeciente. Zack
McDermott se pregunta: “¿Qué vistes el primer día de regreso al trabajo después de 90 días de ausencia debido a un brote psicótico?"5 (12); así comienza su artículo en The New York Times.

Hace en él un llamado desesperado en el que revela la verdad consabida, aduciendo que, cuando se trata de un trastorno mental, uno "no tiene más control sobre esas cosas que un paciente oncológico sobre el estado de sus nódulos linfáticos" ${ }^{\prime 6}(12)$.

Nos comenta su travesía en su retorno al trabajo en una asesoría legal tras el episodio sufrido, y cómo, por la presión sentida a causa del estigma, terminó dejando lo que supo ser el trabajo de sus sueños.

Hasta tal punto llegó el estigma: hasta hacerle abandonar su trabajo.

Esta situación lo motivó a la escritura de un libro (13), y a nosotros a algunas reflexiones que podemos hacer.

Volvemos a la pregunta con la que inició su artículo en el afamado periódico neoyorquino, donde irónicamente fue a hablar de un difamado tema: “QQué vistes el primer día de regreso al trabajo después de 90 días de ausencia debido a un brote psicótico?".

Nuestro idioma nos permite jugar con la homofonía del término vistes, de vestir, y viste, de ver. Por eso parafraseamos la pregunta y reformulamos: “¿Qué viste, en mí, el primer día de regreso al trabajo después de 90 días de ausencia debido a un brote psicótico?". A causa del estigma, podríamos conjeturar que una respuesta podría haber sido: "Lo que he visto, es que vistes los infames ropajes de la locura".

Aun cuando el episodio haya concluido o esté en remisión, el paciente externado queda concebido como el loco que ha regresado, sin siquiera aventurarse uno a pensar que el loco es un sinónimo de padeciente, por lo que lo que es preciso que reciba atención profesional sanitaria, y no exclusión ni discriminación de ningún tipo.

Es en ese punto que podemos mensurar la vigencia del pensamiento falretiano, preocupado por la reinserción social de los pacientes luego de una internación psiquiátrica. Y también para reconocer lo poco que hemos avanzado en todo este tiempo.

La crítica a este escaso progreso la hallamos presente en Franco Basaglia (14), y muy posiblemente a esta exclusión haya contribuido la existencia de los asilos monovalentes. Existencia sobredeterminada por la reticencia social y médica a alojar en los hospitales generales a la locura, a incluir a la denominada salud mental en la salud más general. Existencia que, por un lado, permitió el estudio y el tratamiento especializado y pormenorizado de la patología mental, pero como efecto colateral sostuviera el aislamiento del paciente psiquiátrico y terminara por transformarse en una iatrogenia.

Saludamos jubilosos el proceso de desmanicomialización cuando implica el progresivo abandono del modelo asilar en favor de un modelo asistencial renovado. Pero seguimos al pie de la letra las recomendaciones de 
la Organización Mundial de la Salud (1) cuando nos advierte que la "desinstitucionalización [...] no es sinónimo de deshospitalización", y que "Cerrar hospitales psiquiátricos sin alternativas comunitarias es tan peligroso como crear alternativas comunitarias sin cerrar hospitales psiquiátricos".

Lo que intentamos advertir es que la sustitución del modelo manicomial no se lleve adelante sin una transformación de fondo, y para lograrla, creemos como fundamental el llevar adelante esfuerzos para combatir el estigma.

\section{Lo lejano de la atención cercana en salud mental}

El 2020 en Argentina ya está aquí, con manicomios y sin que las alternativas comunitarias brinden la respuesta necesaria a las problemáticas de salud mental.

Mucho se ha avanzado, y el plantear un destino es un paso importante para saber adónde queremos llegar. Pero los obstáculos que nos salen al paso parecen tener más la complejidad de lo social que de las decisiones políticas.

El panorama de actualidad lo vemos plasmado en una serie de estudios llevados a cabo $(15,16,17)$. El primero nos permite percibir de dónde partimos. Nos muestra la situación de salud mental en todo el país con datos del año 2005 (15), donde relevándose el 97\% de los centros de atención primaria de la salud del territorio argentino, se evalúa que sólo en un 30\% de ellos había atención de psiquiatras y/o psicólogos. Era de esperar que tras la implementación del Plan Federal de Salud (18) y su apoyo a la estrategia de atención primaria, la situación mejorase ostensiblemente. A pesar de ello, nos encontramos, por ejemplo, con que en dos centros urbanos del centro del país, el Departamento General San Martín, de Córdoba y el Nodo Rosario, de Santa Fe, si bien nos hemos acercado al horizonte planteado, aún estamos lejos de llegar al destino buscado.

En ambos casos se cuenta con el esquema sanitario de efectores de primer nivel de atención insertados en la comunidad, con el respaldo de una mayor complejidad de la atención y la posibilidad de internación en hospitales generales y monovalentes que hacen de cabecera. Pero el circuito culmina en una deficiente accesibilidad a la atención primaria en salud mental por diversos motivos.

En el panorama cordobés (16), al año 2018 se detallaba la dificultad de obtención de turnos, listas de espera y la insuficiente disponibilidad de medicamentos como motivos que disuadían de la búsqueda, obtención y efectivización de tratamientos; y que en caso de persistir en su afán de recibirlo, tropezaban con la dificultad geográfica y económica del desplazarse hasta efectores de segundo nivel donde conseguirlo.

En el caso santafesino (17), se describían como obstáculos para la atención comunitaria de salud mental la no asignación de recursos humanos en todos los centros de atención primaria ${ }^{7}$, fallas organizativas que dan lugar a una disparidad entre la oferta y la demanda potencial de asistencia; centros de atención primaria que cuentan con 34 horas asistenciales de psicología y una población potencial de 4.500 habitantes, y otros con 15 horas asistenciales ofertadas para una población potencial de 30.000 habitantes, y dificultades en la articulación intra e intersectorial para las intervenciones en crisis y las internaciones en hospitales generales.

¿Por qué sucede eso? Las respuestas no las tenemos; tan sólo podemos atrevernos a hacer hipótesis al respecto o a plantear preguntas que tal vez nos guíen. ¿Es por el estigma? ¿Es por la tendencia a desestimar a la enfermedad mental, ya sea por la vía de la despatologización, o la del "no es nada"? Ciertamente no podemos descontar tampoco otros factores, como las decisiones políticas y los contextos económicos.

Sea como sea, los estudios citados nos hablan de "valoración de los pacientes de inutilidad de los tratamientos" (17) y del obstáculo simbólico de preconceptos asociados a la locura que "generan reticencia a acceder a la atención" (16). El denominador común de ambas cuestiones es el desconocimiento, que lleva a no contemplar una terapéutica posible, y al prejuicio que se viste de estigmatización.

Al respecto, las directivas de la Organización Mundial de la Salud son claras (1). Nos indica que "La estigmatización se combate también realizando campañas de información pública para educar e informar a la comunidad acerca de la naturaleza, el alcance y las repercusiones de los trastornos mentales", a la vez que nos recuerda que los mismos son un asunto sanitario: "No son sólo variaciones dentro de la 'normalidad', sino fenómenos claramente anormales o patológicos".

\section{Algunas consecuencias del estigma}

La nosografía psiquiátrica se ha mostrado en la historia como el terreno más fértil para la apropiación de sus términos por parte de la sociedad, para un uso peyorativo.

Para muestras tenemos los históricos casos de la imbecilidad (19), el idiotismo (20) y el cretinismo (21), que han sido por la sociedad vaciados de su contenido médico, y utilizados como insultos. Pero también tenemos como ejemplo la más habitual de la cotidianeidad con los comentarios "Este hombre está loco", "Esta mujer es una histérica".

Esto ha llevado a la psiquiatría a rever y renombrar su nosografía, en un intento de desembarazarse del estigma.

Pero a pesar de ello, éste no lo ha dejado de perseguir jamás.

Tal es así que en recientes años la pregunta llegó a la locura cardinal: la esquizofrenia.

Este trastorno mental parece estar condenado al cambio constante de su nombre. Desde la dementia praecox a su nombre actual en la depuración de la terminología

7- Si bien el estudio es del año 2013, una nota periodística del año 2018 nos mostraba que "Sólo hay 7 psiquiatras para 1.500 pacientes en 33 centros de salud", por lo que la situación no debe de ser muy distinta al día de hoy. En: Barrandeguy T. Solo hay 7 psiquiatras para 1.500 pacientes en 33 centros de salud. La Capital, 18/8/2018 
psiquiátrica por parte de Eugen Bleuler en su obra culmine (22), llega al día de hoy una pregunta que se ha hecho la comunidad psiquiátrica, interrogada también por un grupo de profesionales argentinos: Esquizofrenia, ¿es tiempo de cambiar el nombre? (23), y todo en razón del estigma asociado a dicho apartado de la nosografía psiquiátrica.

Los resultados de la consulta fueron que, a pesar de que el término es concebido en un $64 \%$ como conceptualmente correcto, no deja de estar envuelto de estigma.

Sorprende ésta estigmatización de la nosografía psiquiátrica, porque en ocasiones es acompañada de una psicopatologización de la vida cotidiana, donde la gente ya no está triste, sino deprimida.

Tal vez sea porque existen algunas patologías que no son estigmatizadas, pero sí trivializadas.

Existe en la historia de la farmacología la brillante publicidad de un laboratorio que, al hablar de su presentación de fluoxetina, se quejaba del movimiento que estaba "Trivializando una seria enfermedad", al tomar a la depresión como una simple tristeza pasajera, y no como la grave patología mental que es.

En la misma vía van los espectáculos que ridiculizan al trastorno obsesivo compulsivo y sus diversas presentaciones clínicas, bajo la rúbrica vulgarizada del TOC.

No debemos perder de vista tampoco esas manifestaciones. El hecho de que se presenten con un rostro diverso al insulto no los hace menos grave, sino incluso hasta más preocupante, porque estigmatiza y ridiculiza a los trastornos mentales de manera subrepticia.

\section{El estigma no se reduce ni al trastorno ni al pade- ciente, sino que también toma al tratante}

Obras actuales dedicadas al tema del estigma nos destacan un hecho: el estigma también recae sobre el tratante.

Un trabajo del 2018 nos muestra los rostros que toma el estigma: las enfermedades mentales no son verdaderas enfermedades; los psiquiatras no son verdaderos médicos y están tan locos como sus pacientes; no han podido hacer otra especialidad mejor (24).

Esto llevó a que Marcelo Cetkovich, en el mismo afán filantrópico que motivó a Pinel, llegara a decir que "La psiquiatría no es glamorosa" (25).

En su obra denuncia cómo "Los tratamientos médicos son descalificados con términos como 'chaleco químico'", a la par que determinados movimientos pugnan ya no por la desmanicomialización, sino por la deshospitalización y hasta la despatologización de la locura. Estas medidas creemos que no van en vías de otra cosa que no sea la estigmatización misma de la psiquiatría, desprestigiando y cuestionando sus prácticas sanitarias, calificando a la psiquiatría como dispositivo disciplinario (26) -sin considerar su crucial papel sanitario- y presentando al psiquiatra mismo como un agente de represión (27).

La postura de este artículo es contraria a los postulados de este último punto. Si bien nos posicionamos a favor de la integración de los servicios de psiquiatría en los hospitales generales -por creer que redundará en una mayor integración de la denominada salud mental en la salud más general, y del paciente psiquiátrico en la sociedad- no conciliamos con una mirada crítica más destructiva que constructiva de la psiquiatría.

La pregunta sería: y si no es la medicalización de la locura, ¿qué debería ser? Ciertamente, nunca más debería ser el período pre-médico. Por nuestro lado la situación es clara: si lo que se busca es combatir el estigma, la solución no es combatir la psiquiatría. La psiquiatría ha sido desde el comienzo la alternativa dignificante del loco como enfermo, disminuyendo todo el oscurantismo del período pre-médico.

La más somera revisión histórica nos ha enseñado cómo el estigma estuvo presente desde antes del nacimiento mismo de la psiquiatría, aguardando a su advenimiento, para luego impregnarla a ella también con su infame marca.

\section{Las controversias de la ley}

Entre los escritos que guían y rigen nuestras prácticas en el campo de la medicina mental, nos encontramos con el manual de Atención de las urgencias de salud mental (28). En este escrito se reconoce que "La internación es considerada como un recurso más dentro de la estrategia terapéutica", una opción viable y hasta precisa en episodios de descompensación que procura el restablecimiento del paciente a un estado anterior de salud que se supone, o al menos, de estabilización.

Este postulado sigue de cerca las indicaciones de los organismos sanitarios internacionales que sostienen los hospitales polivalentes como red de apoyo a las instituciones comunitarias para la internación durante las crisis subjetivas $(1,29)$. Pero entre esta habilitación a la internación de medicina mental, y la calificación que de ella hace la Ley Nacional de Salud Mental (30) en su capítulo VII, hay un abismo.

Se comprende que la internación deba ser llevada a cabo sólo cuando aporte mayores beneficios que las intervenciones en la comunidad, que debe ser lo más breve posible, y estar orientada a fines terapéuticos. Pero no se comprende el porqué de calificar a la misma como "un recurso terapéutico de carácter restrictivo". En este punto va nuestra crítica a la Ley Nacional de Salud Mental.

La valoramos en el sentido de reconocimiento de derechos humanos del paciente psiquiátrico, que se traduce en un reconocimiento del mismo como humano, y por tanto sujeto de tales derechos inherentes a su condición. También por la definición allí expuesta de la salud como "proceso determinado por componentes históricos, socioeconómicos, culturales, biológicos y psicológicos", ya que ofrece una mirada más integral sobre el estado de salud, que una mirada cercenadora de la dimensión social del padeciente.

Pero creemos que la estigmatización para con la locura se infiltra en la ley misma al calificar al recurso terapéutico que es la internación, avalado incluso por la Organización Mundial de la Salud, como "restrictivo".

Llama la atención tal enunciado porque alude a lo 
restrictivo de la internación psiquiátrica, y no de la internación en general. A nadie se le ocurriría aducir jamás que una internación dictada por el personal de cardiología a un paciente hipertenso tras un accidente cerebrovascular sea de carácter restrictiva. Pero cuando se trata de una internación psiquiátrica, pareciera que es una internación de otra índole.

Esto no es otra cosa que lo que venimos denunciando en todos estos artículos: estigma en psiquiatría.

Debemos ser muy cuidadosos con las palabras que utilizamos, pues podemos provocar el efecto contrario al buscado. Si lo que se busca es una ley más inclusiva y combatir el estigma, al decir que la internación psiquiátrica es restrictiva no hacemos más que fomentar en el imaginario social que las disciplinas encargadas de brindar asistencia sanitaria a las personas con padecimiento mental, son disciplinas perjudiciales en vez de asistenciales, llevando así a que las personas vean cada día con más recelo a los profesionales, y estén cada vez menos dispuestos a aceptar la ayuda profesional y acudir a ella.

A este respecto de las palabras y los nombres, es que introducimos el segundo apartado de nuestra crítica. Consideramos oportuna la denominación de usuarios cuando se hace referencia que el usuario lo es de un servicio, en este caso, de asistencia sanitaria. Pero no podemos permitirlo si esta denominación va en detrimento de otra denominación clave.

No podemos permitir jamás que el usuario vaya reemplazando hasta borrar del todo al paciente. Porque creemos que el término paciente es un término que llena al padeciente de dignidad médica.

El cómo llamamos a nuestros pacientes importa. Creemos que el término paciente no es excluyente del usuario, pudiendo darse la coexistencia de ambos. Pero debemos procurar que el usuario no termine aboliendo al paciente, y viceversa: que el término paciente tampoco termine obturando todas las otras dimensiones que hacen a la persona que en parte, y tan sólo en parte, padece de algún trastorno mental.

El término paciente está íntimamente ligado al de padeciente, como "El que soporta males" (31). Lo introduce en la lógica del par salud/enfermedad, de la atención sanitaria y del tratamiento, e incluso de la cura y la restitutio ad integrum. Creemos que no hay nada menos estigmatizante que la condición de paciente, pues el imperativo médico es "Haz todo lo que está en tu poder para hacer de nuevo posible lo que es provisionalmente imposible, pero de lo cual todo humano es declarado axiomáticamente capaz" (32), planteando el episodio como pasajero, con la esperanza de la recuperación.

En cambio, tememos que la hegemonía del término usuario termine llevando a la idea que el estado de salud sea meramente una opción, de la cual la persona hace uso -como usuario que es- o no, en vez de una contingencia que toma a la persona contra su voluntad, y de la cuál merece y tiene todo el derecho a recibir asistencia profesional en su ayuda. Eso sí sería estigmatizante.

No olvidemos a este respecto que "No se vuelve loco el que quiere" (33); el trastorno mental no es una opción.

\section{Una conclusión de... ¿cierre?}

El recorrido por la historia cumple los objetivos de rescatar a los inmortales nombres que hicieron por primera vez la senda que hoy transitamos, y marcar cómo se empeñaron en la misma lucha que nosotros hoy nos proponemos encarar e instamos a la unión de esfuerzos mancomunados de las profesiones de la salud más general.

Es también una búsqueda etiológica, para hallar tal vez alguna luz que nos ayude en el camino a recorrer, y también que nos ilumine con los ejemplos de los grandes médicos que hicieron a la historia de la psiquiatría.

Creemos que cualquier esfuerzo que se proponga hacer será en vano si no estamos advertidos de los fundamentos. Este escrito busca eso: servir de base para ulteriores desarrollos, proponer más material a la causa, y así realzar la importancia destacada que debe tener la lucha contra el estigma en la psiquiatría.

Algunas de las enunciaciones hechas en el material ofrecido tal vez puedan resultar controversiales, otras quizás incluso criticables. Lo que no serán nunca es libres de toda rectificación posible, y por eso es que la cuestión no pasa a estar cerrada. Pero mientras se logre poner en debate algunas cuestiones centrales -sin que el resto de las proposiciones obturen su emergencia- el objetivo de este artículo puede considerarse cumplido.

El material ofrecido son nuestras reflexiones. Allí se cuenta la revalorización del papel que supo cumplir la medicalización de la locura, y del concepto de paciente. Pero en ella no dejamos de estar advertidos que si bien lo sostenemos, no propendemos a una exaltación de lo uno en detrimento de algo otro.

También rescatamos como puntos centrales la necesidad de continuar trabajando para hacer efectiva y consolidar la atención de salud mental en la comunidad, y por supuesto la temática de las campañas de educación sobre patología mental.

Confiamos que el avance del conocimiento se traslucirá en mejores abordajes terapéuticos del sufrimiento mental. Y que éste deberá ser llevado a cabo en la interdisciplina, conceptualizando a la salud de manera integral.

Pero creemos que no lo lograremos jamás si no emprendemos antes una lucha contra el estigma que rodea a lo psiquiátrico y que nos impide en cierta manera continuar dando pasos.

Porque si no, la atención cercana, en la comunidad, de la salud mental, seguirá siendo lejana. Porque la articulación intra e intersectorial se verá dificultada, y nos seguiremos topando con las mismas dificultades que alguna vez señalara Franco Basaglia: "Un individuo enfermo tiene como primera necesidad, no sólo la cura de la enfermedad, sino muchas otras cosas" (14). Allí aparecen los problemas habitacionales y alimenticios que no podremos solucionar si la articulación intersectorial no se lleva a cabo.

Porque nuestro papel como profesionales de la salud no se reduce a la clínica, sino que también debemos exigir a quienes deban tomar decisiones e implementar acciones que las hagan. Y debemos ser los primeros en 
expresarnos y llevar adelante la campaña en contra de la estigmatización. Es la dimensión social que tiene nuestra práctica.

Quizás tan sólo así podamos cumplir con el papel liberador que nos indicara Henry Ey para la psiquiatría. Si el paciente ha de ser "para el médico que lo toma a su cargo [...] el sujeto de la constante necesidad de hacerle recuperar su libertad" (27), esto también puede aplicar en lo que se refiere a liberarlo del estigma.

\section{Declaración de conflictos de interés}

El autor declara no tener conflictos de interés en relación con el presente artículo.

\section{Referencias bibliográficas}

1. Organización Mundial de la Salud. Informe sobre la salud en el mundo 2001 - Salud mental: nuevos conocimientos, nuevas esperanzas. Ginebra, Suiza: Organización Mundial de la Salud, 2001.

2. Corominas J (2000) "Estigma", en Breve diccionario etimológico de la lengua castellana. Madrid: Gredos, p. 256.

3. Saunders WB (1985) "Estigma", en Diccionario enciclopédico ilustrado de medicina Dorland, Vol. 1. Madrid: Interamericana, p. 573.

4. Charcot JM (2003) Histeria. Jaén: Ediciones del lunar.

5. Ingenieros J (2007) Histeria y sugestión. Córdoba: Buena Vista.

6. Esquirol JE ([1805] 2012) Las pasiones consideradas como causas, síntomas y medios curativos de la alienación mental", en El nacimiento de la psiquiatría. Buenos Aires; Polemos; 2012.

7. Falret JP ([1864] 2015) Las enfermedades mentales y los asilos para alienados. Buenos Aires: Polemos.

8. Foucault M (2014) Historia de la locura en la época clásica. Buenos Aires: Fondo de Cultura Económica.

9. American Psychiatric Association. Mental health month. End stigma [Internet]. Disponible el 4/11/2019 en: https://www. twitter.com/APAPsychiatric/status/1129863542151233540

10. American Psychiatric Association. Fighting stigma: how to respond to inappropriate and insensitive comments about mental health [Internet]. Disponible el 4/11/2019 en: https://www.psychiatry.org/news-room/apa-blog/2016/11/ fighting-stigma-how-to-respond-to-inappropriate-and-insensitive-comments-about-mental-health

11. American Psychiatric Association. What is mental illness? [Internet]. Disponible el 4/11/2019 en: https://www.psychiatry.org/patients-families/what-is-mental-illness

12. MacDermott $Z$. The 'madman' is back in the building. The New York Times, 20/9/2017.

13. MacDermott Z (2017) Gorilla and the bird: a memoria of madness and a mother's love. EEUU: Hachette Book Group.

14. Basaglia F (2013) La condena de ser loco y pobre. Buenos Aires: Topía.

15. Ballesteros M. Profesionales de la salud en el primer nivel de atención de Argentina. Un análisis sobre las desigualdades jurisdiccionales. Geograficando, 2016, Vol. 12 (2). Universidad Nacional de La Plata.

16. Bosco F, Galindez L. El derecho a la atención en salud mental: un análisis desde la accesibilidad. Anuario de investigaciones de la Facultad de Psicología, 2018, Vol. 3 (3). Universidad Nacional de Córdoba.
17. Belizán J, Borda M, Cisneros C, Dávila A, Huerta A, Quadri A, Rodriguez A. Acceso a la atención en salud mental en centros de salud provinciales y municipales de la ciudad de Rosario. Investigación en salud, 2013, Vol 10 (1). Secretaría de Salud Pública Municipal. Rosario.

18. Plan Federal de Salud 2004 - 2007 (2004) Ministerio de Salud de la Nación. Presidencia de la Nación. Buenos Aires, Argentina.

19. Saunders WB (1985) "Imbecilidad", en Diccionario enciclopédico ilustrado de medicina Dorland, Vol. 2. Madrid: Interamericana, p. 798.

20. Pinel P. ([1809] 2012) "Tratado médico - filosófico sobre la alienación mental", en El nacimiento de la psiquiatría. Buenos Aires: Polemos.

21. Cotran R, Robbins S. (1987) "Cretinismo", en Patología estructural y funcional. México: Interamericana, pp. 1183-1184.

22. Bleuler E ([1911] 2012) Demencia precoz, o el grupo de las esquizofrenias. Buenos Aires: Polemos.

23. Seré L, Cardona D, Flichtentrei D, Lopez P, Prats M, Mastandueno R, Miorelli A, Maruta T, Cetkovich M. Schizophrenia: is it time to rename it? The opinions of latin american psychiatrists. Schizophrenia research, Vol. 178. 2016.

24. Mendoza Gaitan E, Onofrio G (2018) Estigma en psiquiatría: perspectivas y nudos. Guatemala: APAL Ediciones.

25. Cetkovich M (2018) El estigma de la enfermedad mental y la psiquiatría. Buenos Aires: Paidós.

26. Foucault M (2012) El poder psiquiátrico. Buenos Aires: Fondo de Cultura Económica.

27. Ey H. La psiquiatría y la privación de la libertad. Revista de psiquiatría del Uruguay, 2004, Vol. 68 (1).

28. Atención de las urgencias de salud mental (2019). Ministerio de Salud y Desarrollo Social. Dirección Nacional de Salud Mental y Adicciones. Presidencia de la Nación. Buenos Aires.

29. Organización Mundial de la Salud (1990) Declaración de Caracas.

30. Ley Nacional de Salud Mental y Adicciones. Ley Nro. 26657/10. Ministerio de Salud. Presidencia de la Nación. Buenos Aires; 2011.

31. Corominas J (2000) "Paciente", en Breve diccionario etimológico de la lengua castellana. Madrid: Gredos, p. 432.

32. Badiou A (2000) Reflexiones sobre nuestro tiempo. Buenos Aires: Ediciones del cifrado.

33. Lacan J (2015) "Acerca de la causalidad psíquica", en: Escritos 1. Buenos Aires; Siglo XXI. 